\title{
Cognitive predictors of physical activity behaviors among rural patients with type 2 diabetes: applicability of the Extended Theory of Reasoned Action (ETRA)
}

This article was published in the following Dove Press journal:

Journal of Multidisciplinary Healthcare

\author{
Ehsan Sarbazi' \\ Fatemeh Moradi ${ }^{2}$ \\ Saber Ghaffari-Fam ${ }^{3,4}$ \\ Katayoon Mirzaeian ${ }^{2}$ \\ Towhid Babazadeh ${ }^{5}$ \\ 'Department of Epidemiology, Health \\ Faculty, Student Research Committee, \\ Tabriz University of Medical Sciences, \\ Tabriz, Iran; ${ }^{2}$ Department of Health, \\ Urban Management, Senior Expert in \\ Director General Office of Health, \\ Tehran Municipality, Tehran, Iran; ${ }^{3}$ Road \\ Traffic Injury Research Center, Tabriz \\ University of Medical Sciences, Tabriz, \\ Iran; ${ }^{4}$ School of Nursing of Miandoab \\ City, Urmia University of Medical \\ Sciences, Urmia, Iran; ${ }^{5}$ Department of \\ Public Health, Sarab Faculty of Medical \\ Sciences, Sarab, Iran
}

Background: This study aims to examine the cognitive-behavioral determinants of physical activity behaviors (PABs) of patients diagnosed with type 2 diabetes.

Subjects and methods: In this cross-sectional study, census sampling was employed to enroll 120 rural patients with type 2 diabetes in the Chalderan County in 2015. To collect data, a valid and reliable instrument, based on the Extended Theory of Reasoned Action (ETRA) constructs, was used. Data were analyzed by SPSS 21 software using descriptive and inferential statistical methods.

Results: Using the one-way ANOVA test, it was found that PABs had statistically significant correlation with all ETRA constructs except subjective norms $(\mathrm{P}=0.574)$. Knowledge $(\mathrm{P}=0.015)$, self-efficacy $(\mathrm{P}<0.001)$ and behavioral intention $(\mathrm{P}<0.001)$ had a significant association with $\mathrm{PABs}$, respectively. Also, ETRA structures were able to reflect $41.0 \%$ of the behavioral changes. Among structures, knowledge ( $\mathrm{P}=0.014)$, selfefficacy $(\mathrm{P}<0.001)$, and behavioral intention $(\mathrm{P}=0.020)$ were significant predictors of PABs $(\mathrm{R} 2=0.414)$.

Conclusions: Health care providers may consider the ETRA an appropriate framework to design educational interventions aimed at improving PABs among rural patients with type 2 diabetes.

Keywords: diabetes mellitus, type 2, physical activity, self care

\section{Introduction}

Diabetes is one of the most common metabolic diseases worldwide and also in Iran. ${ }^{1}$ According to the WHO report of 2016, there are approximately 422 million diabetic adults globally, ${ }^{2}$ and it is estimated that this number would reach 438 million in 2030; this is due to population aging, population growth, and lifestyle changes. ${ }^{3}$ It, also, imposes financial, psychological, and social costs on individuals, families, and society. ${ }^{4}$

The WHO report in 2012 revealed that approximately 1.50 million deaths were directly caused by diabetes and another 2.20 million deaths were pertained to high blood glucose. ${ }^{5}$ In addition to the increased mortality, diabetes can lead to decreased physical function, negative influence on mental health, chronic diseases such as cardiovascular disease, ${ }^{6,7}$ and a decreased quality of life of the patients. ${ }^{7}$ To prevent the complications of diabetes, the use of nonpharmacological approaches such as healthy nutrition education and regular physical activity can be helpful. ${ }^{8}$
Correspondence: Towhid Babazade Department of Public Health, Sarab Faculty of Medical Sciences, Sarab 5I6566593I, Iran

Tel +989369941618

Fax +984445332147

Email Towhid.babazadeh@gmail.com 
The sedentary lifestyle is one of the most important modifiable factors of diseases such as diabetes. ${ }^{9}$ Evidence indicates that physical activity, in addition to a reduction in metabolic risks, can be effective in weight management, improving blood glucose and lipid profiles in diabetic patients. Furthermore, some studies suggest long-term effects of physical activity in controlling diabetes. ${ }^{10}$ Despite the positive effects of physical activity in the prevention and control of diabetes, some studies show that diabetic patients have less mobility compared to healthy people. ${ }^{11}$ This sedentary lifestyle can be caused by various factors. Identifying and understanding the factors affecting the lifestyle of diabetic patients can be helpful to health care providers in the design and implementation of preventive interventions. ${ }^{12}$

Previous studies have suggested using behavior change theories and models to create and maintain physical activity due to its complexity can be helpful. ${ }^{13}$ The theories can provide a rational framework for designing interventions and also act as a guide for their evaluation. ${ }^{14}$ The Theory of Reasoned Action (TRA) focuses on the individual and interpersonal factors, such as attitudes, subjective norms, and the way they influence behavioral intentions and, in turn, behaviors. ${ }^{15}$ This theory is successful in predicting behaviors that are fully under the voluntary control of people but is not sufficient to examine the behaviors by individuals that are not fully volitional. ${ }^{13}$ Owing to this deficiency, the TRA has been further developed by adding the construct of perceived behavioral control (PBC). PBC is defined as the perceived ease/difficulty of performing an action. ${ }^{16}$ Although Ajzen argues that self-efficacy and $\mathrm{PBC}$ are synonymous, Bandura believes that the concept of self-efficacy is broader than PBC. ${ }^{17}$ Moreover, the results of several studies have shown that self-efficacy could be better than $\mathrm{PBC}$ in predicting behavioral intention and behavior. According to these findings, the researchers used the theory of self-efficacy along with other structures of the TRA and named it the Extended Theory of Reasoned Action (ETRA). These studies have shown that the TRA, along with self-efficacy, can be valuable in predicting behavioral intentions and behaviors such as substance abuse prevention, and oral health. ${ }^{18}$ Likewise, the study conducted in Iran by Didarloo et $\mathrm{al}^{19}$ among women with type 2 diabetes reported that significant correlation existed between independent constructs and model-related dependent constructs. For instance, the presence of a significant association between attitudes and intention to perform self-care among diabetic women
( $\beta=0.199, p=0.001)$, as well as ETRA model along with three model constructs (attitude, subjective norms, and self-efficacy), explained $41.5 \%$ of variance of intentions and $25.3 \%$ of variance of actual behavior.

This study was performed to assess the cognitive and demographic variable predictors of physical activity behaviors (PABs) among patients with type 2 diabetes in a rural area using ETRA. The identification of the determinant factors may be beneficial in developing interventional measures aimed at promoting physical activity.

\section{Subjects and methods Research design}

This cross-sectional study was performed on rural patients with type 2 diabetes in Chalderan city, West Azerbaijan Province, Iran. The study period was 3 months: May to July 2015. The target population comprised all type 2 diabetic patients within that area.

\section{Setting and sample}

According to the available medical records in the health network, 139 patients with type 2 diabetes lived in the rural area of Chalderan. However, 15 people were excluded from the main study due to their participation in the pilot study and four refused to take part. Therefore, the study was conducted on 120 participants.

The inclusion criteria for the study were: living in a rural area in Chalderan County; being over 30 years old; having a medical record as a type 2 diabetes patient in the health network. Exclusion criteria were: having other types of diabetes (type I or pregnancy) and refusal to participate in the study.

\section{Data collection and instruments}

The data collection tools were valid and reliable questionnaires. ${ }^{13}$ As this instrument was developed in Persian, to be used among patients with type 2 diabetes, no prior specific change was required. An expert panel (including two health educationists and two endocrinologists) confirmed its validity. In order to assess the reliability, a pilot study was conducted on 15 patients with type 2 diabetes, who were not included in the final sample. The Cronbach's alpha of the scales was calculated in the pilot and main study as well as the scales, number of items, reliability coefficients, and possible ranges of the constructs (Table 1). 
Table I Descriptive statistics for Extended Theory of Reasoned Action (ETRA) variables

\begin{tabular}{|c|c|c|c|c|c|}
\hline $\begin{array}{l}\text { ETRA } \\
\text { constructs }\end{array}$ & $\begin{array}{l}\text { Number of } \\
\text { items }\end{array}$ & $\begin{array}{l}\text { Possible } \\
\text { range }\end{array}$ & $\begin{array}{l}\text { Mean } \\
( \pm S D)\end{array}$ & $\begin{array}{l}\text { Cronbach } \alpha \text { in the pilot } \\
\text { study }\end{array}$ & $\begin{array}{l}\text { Cronbach } \alpha \text { in the main } \\
\text { study }\end{array}$ \\
\hline Knowledge & 11 & $0-22$ & $7.40(2.9)$ & 0.79 & 0.77 \\
\hline Attitude & 4 & $4-20$ & $10.48( \pm 1.9)$ & 0.81 & 0.85 \\
\hline Subjective norms & 4 & $4-20$ & $11.19( \pm 2.8)$ & 0.88 & 0.83 \\
\hline Self-efficacy & 4 & $4-20$ & $10.83( \pm 2.8)$ & 0.87 & 0.92 \\
\hline $\begin{array}{l}\text { Behavioral } \\
\text { intention }\end{array}$ & 2 & $2-10$ & $5.58( \pm 2.1)$ & 0.90 & 0.95 \\
\hline
\end{tabular}

Note: The Cronbach's alpha is measured $0.77-0.95$ for the ETRA.

With respect to instrument, it is noteworthy that demographic characteristics included six items: gender, age groups $(30-39,40-49, \geq 50)$, level of education, marital status, job, household monthly income. Knowledge of diabetes was measured using 11 multiple-choice items. An example of the items is: "What are the early complications of diabetes?" Correct answers scored 2, incorrect ones 0 ; and "do not know" response, 1. The possible scores ranged from 0 to 22 .

The ETRA questionnaire included four constructs: attitude (eg, "I think that doing regular daily physical activity can lead to regulated blood sugar levels, improved health and happiness of the people"), subjective norms (eg, "my family supports me in doing appropriate exercise"), self-efficacy (eg, "I am able to do physical activity every day"), and behavioral intention (eg, "I intend to perform physical activity regularly within the coming month"). For all four constructs, the items were rated on a 5-point Likert scale ranging from 1 to 5 ( $1=$ totally disagree through to $5=$ totally agree). The minimum score in structures of attitude, subjective norms, and self-efficacy was 4 and the maximum 20 , whereas the minimum score in the behavioral intentions was 2 and the maximum 10 .

Finally, to assess the levels of diabetes selfmanagement, the summary of diabetes self-care activities measure was used. ${ }^{20}$ Physical activity behaviors were measured with the two items following :

1) On how many of the last SEVEN DAYS did you participate in at least 30 minutes of physical activity? (Total minutes of continuous activity, including walking).

2) On how many of the last SEVEN DAYS did you participate in a specific exercise session in (as riding a bike, swimming ...) other than what you do around the house or a as part of you work?
In this instrument, the participants declared the number of days they did the recommended physical activities over the past seven days. Response categories included a 7-point scale ranging from 0 to 7 . Total possible scores ranged from 0 to 14 , in which higher scores were representative for higher PABs on the part of the participants.

\section{Statistical analysis}

Data were analyzed by applying SPSS software (Version 20.0, Chicago, IL, USA) and presented with the frequency and mean $( \pm \mathrm{SD})$ of the variables. The possible differences between PABs with demographic variables which were dichotomous were analyzed by independent t-test. In order to determine whether there were any significant differences among the means of three or more independent groups, one-way ANOVA was used.

To assess the differences among ETRA structures which were more than two categories regarding PABs, one-way ANOVA was applied. Additionally, a hierarchical multiple linear regression analysis was utilized to illustrate the variations in PAB scores on the basis of ETRA constructs. Hierarchical regression is a method to demonstrate if the variability of one's interest explains a statistically significant amount of variance in your dependent variable after accounting for all other variables. Predictors for PABs were classified in two different blocks according to their natures: 1 (demographic characteristics block: age group, level of education, household monthly income, and duration of disease; 2 (ETRA block: This block comprised of the five different constructs of ETRA. A P-value $<0.05$ was considered to indicate statistical significance.

\section{Results}

A total of 120 individuals participated in the study. Of these, $53.3 \%$ of the participants were female and $46.7 \%$ male. The majority $(40.0 \%)$ were in the age group of 40 to 49 years, 
while $28.8 \%$ of the participants were in the age group of 30 to 39 years, and $34.2 \%$ were at the age of 50 or higher. Regarding the educational status, $34.2 \%$ of respondents were illiterate, $31.7 \%$ and $33.3 \%$ were literate up to the elementary and secondary levels, respectively. Around $12.5 \%$ reported that their household monthly income was less than 313 dollars, $66.7 \%$ was 313 to 470 dollars, and $20.8 \%$ was more than 470 dollars. The duration of the disease in $23.3 \%$ of the subjects was $<5$ years, in $52.0 \%$ was 5 to 10 years, and in $24.4 \%$ was $>10$ years (Table 1 ).

Examining the cognitive behavioral determinants of PABs of 120 patients diagnosed with type 2 diabetes, the present study revealed that the mean $( \pm \mathrm{SD})$ physical activity of the participants was $1.20( \pm 1.9)$ times per week. Demographic characteristics of the participants are demonstrated in Table 2. In accordance with ANOVA test between age categories and $\mathrm{PABs}$, there was a significant association $(\mathrm{P}=0.032)$. Also, the findings demonstrated a statistically significant association between PABs and education level. Hence, individuals with lower education levels in comparison with those with higher education had lower physical activity $(\mathrm{P}<0.001)$ (Table 2$)$.

Using the one-way ANOVA test, it was found that PABs had statistically correlation with all ETRA constructs except for subjective norms $(\mathrm{P}=0.574)$. Knowledge $(\mathrm{P}=0.015)$, selfefficacy $(\mathrm{P}<0.001)$, and behavioral intention $(P<0.001)$ had a significant association with PABs, respectively. In other words, based upon multiple comparison tests of post hoc, the Scheffe test, and test of homogeneity of variance $(\mathrm{P}<0.05)$, there was a statistically significant difference in PABs of subjects when comparing patients with increased amount of physical activity ( 2 days and more) with those with no or only 1-day activity.

For example, in self-efficacy dimension, in subgroups of 0-2 $\quad(\mathrm{P}=0.077), \quad 0-3 \quad(\mathrm{P}=0.001), \quad 0-4 \quad(\mathrm{P}=0.004), \quad 1-3$ $(\mathrm{P}=0.002)$, and $1-4(\mathrm{P}=0.010)$, statistically significant differences were observed. In behavioral intention dimension, in subgroups of $0-3(\mathrm{P}=0.020), 0-4(\mathrm{P}=0.002), 1-3(\mathrm{P}=0.006)$, and $1-4(\mathrm{P}=0.001)$, the differences were significant. Also in knowledge dimension, in subgroup $0-3(\mathrm{P}=0.050)$, the difference was significant. More explanations of subgroups' physical activity are illustrated in Table 3.

Table 4 represents the hierarchical multiple linear regressions for ETRA constructs and PABs. According to the analysis, demographic variables of the participants approximately reflected $16.10 \%$ of the observed variance in PABs, which was statistically significant at 0.05 levels. At the first step, the variables of age group and level of education

Table 2 Demographic characteristics of the participants and their association with physical activity behaviors

\begin{tabular}{|c|c|c|c|c|c|c|}
\hline Variables & Categories & $\mathbf{N}(\%)$ & Mean (士SD) & $\mathbf{F}$ & Effect size & P-value \\
\hline \multirow[t]{3}{*}{ Age groups } & $30-39$ & $31(28.8)$ & $\mathrm{I} .64( \pm \mathrm{I} .2)$ & \multirow[t]{3}{*}{3.55} & \multirow[t]{3}{*}{0.057} & \multirow[t]{3}{*}{$0.032^{\Omega}$} \\
\hline & $40-49$ & $48(40.0)$ & $\mathrm{I} .14( \pm \mid .2)$ & & & \\
\hline & $\geq 50$ & $4 \mathrm{I}(34.2)$ & $0.92( \pm 0.9)$ & & & \\
\hline \multirow[t]{2}{*}{ Gender } & Male & $64(53.3)$ & $1.14( \pm I . I)$ & \multirow[t]{2}{*}{0.44} & \multirow[t]{2}{*}{0.003} & \multirow[t]{2}{*}{$0.590^{\Omega \Omega}$} \\
\hline & Female & $56(46.7)$ & $1.26( \pm 0.2)$ & & & \\
\hline \multirow[t]{3}{*}{ Education level } & Illiterate & $42(34.2)$ & $0.92( \pm 0.9)$ & \multirow[t]{3}{*}{10.79} & \multirow[t]{3}{*}{0.156} & \multirow[t]{3}{*}{$0.00 I^{\Omega}$} \\
\hline & Elementary & $38(31.7)$ & $0.84( \pm I .0)$ & & & \\
\hline & Secondary & $40(33.3)$ & $\mathrm{I} .85( \pm \mid .2)$ & & & \\
\hline \multirow[t]{3}{*}{ Household monthly income } & $<313$ dollars & $15(12.5)$ & $1.07( \pm \mid .0)$ & \multirow[t]{3}{*}{0.925} & \multirow[t]{3}{*}{0.016} & \multirow[t]{3}{*}{$0.410^{\Omega}$} \\
\hline & $313-470$ dollars & $80(66.7)$ & $\mathrm{I} .48( \pm \mathrm{I} . \mathrm{I})$ & & & \\
\hline & $>470$ dollars & $25(20.8)$ & $\mathrm{I} .48( \pm \mathrm{I} .3)$ & & & \\
\hline \multirow[t]{3}{*}{ Duration of disease } & Less than 5 years & $28(23.3)$ & $1.32( \pm \mid .3)$ & \multirow[t]{3}{*}{0.917} & \multirow[t]{3}{*}{0.015} & \multirow[t]{3}{*}{$0.402^{\Omega}$} \\
\hline & 5 to 10 years & $63(52.5)$ & $1.06( \pm I . I)$ & & & \\
\hline & More than 10 years & $29(24.2)$ & $1.37( \pm 0.9)$ & & & \\
\hline
\end{tabular}

Notes: ${ }^{\Omega}$ p-value was calculated based on ANOVA test, ${ }^{\Omega \Omega}$ p-value was calculated based on $t$-test. 
Table 3 The number of activity days for each subgroup

\begin{tabular}{|l|l|l|l|l|l|}
\hline Subgroups & $\mathbf{0}$ & $\mathbf{I}$ & $\mathbf{2}$ & $\mathbf{3}$ & $\mathbf{4}$ \\
\hline $\begin{array}{l}\text { Days of doing } \\
\text { activity }\end{array}$ & Zero day & One day & $\begin{array}{l}\text { Two } \\
\text { days }\end{array}$ & $\begin{array}{l}\text { Three } \\
\text { days }\end{array}$ & $\begin{array}{l}\text { Four } \\
\text { days }\end{array}$ \\
\hline
\end{tabular}

revealed significant associations with PABs. Similarly, the ETRA constructs were responsible for $41.40 \%$ change in the observed variance which was statistically significant $(\mathrm{P}<0.001)$. Knowledge $(\beta=0.205)$, self-efficacy $(\beta=0.306)$, and behavioral intention $(\beta=0.182)$ indicated significant associations with PABs. Among the significant structures, self-efficacy $(\beta=0.306)$ was the strongest predictor of PABs.

\section{Discussion}

This study was carried out to examine the cognitive determinants of PABs among the patients diagnosed with type 2 diabetes using ETRA in a rural area in Chalderan city, Iran.

The findings of the study indicated that the average PABs were 1.20 times per week among the participating patients suffering from type 2 diabetes which represents the inactivity of the patients. The diabetic patients should perform moderate-intensity physical activities such as hasty walking, swimming, and bike riding for at least $150 \mathrm{mins}$ in the week for at least three nonsequential days. ${ }^{21}$ In line with these findings, Baji et $\mathrm{al}^{22}$ reported that behaviors of physical activity were weak in patients with type 2 diabetes. However, the results of the studies indicate that regular physical activity as a self-care behavior could have an important role in controlling the complications of diabetes. ${ }^{23,24}$ Likewise, according to a meta-analysis, physical activity and risk of type 2 diabetes have an inverse correlation; it is worth mentioning that reduced adiposity might mediate the issue. ${ }^{25}$

Therefore, it seems necessary to focus on physical activity and to identify the factors affecting it. As a result, it can be helpful in designing effective interventions to promote physical activity in type 2 diabetes patients.

It was found that patients of older ages $(\geq 50)$ had a lower average of PABs. It is similar to the results of previous studies in other countries ${ }^{25}$ and in Iran. ${ }^{13}$ These findings suggest that increasing age is associated with decreasing selfcare behaviors to avoid making causal implications. Consequently, it is recommended to make educational interventions aimed at improving PABs in diabetic patients of older ages in health care centers and clinics.

In the current study, PABs were higher among literate patients. This finding was consistent with previous studies. ${ }^{13}$ One of the reasons for the lower level of physical activity in people with lower educational level can be that the level of health literacy among uneducated people is low. A study showed that age group (below or above 65 years old) was the most important predictor of overall activity level. It is to say that $4.8 \%$ of the variance in the physical activity level and self-efficacy as a correlate is positively associated with adoption and maintenance of physical activity. ${ }^{26}$ In another study, low education was associated with a lack of moderate-to-

Table 4 Hierarchical regression analysis to predict physical activity behaviors

\begin{tabular}{|c|c|c|c|c|c|c|}
\hline \multirow[t]{2}{*}{ Step/Variable } & \multicolumn{3}{|l|}{ Step I } & \multicolumn{3}{|l|}{ Step 2} \\
\hline & $\begin{array}{l}\text { Standardized beta } \\
\text { coefficient }\end{array}$ & $P$-value & $\mathbf{R}^{2}$ & $\begin{array}{l}\text { Standardized beta } \\
\text { coefficient }\end{array}$ & $P$-value & $\mathbf{R}^{2}$ \\
\hline (I) Age groups & $-0.210 *$ & 0.020 & \multirow[t]{5}{*}{0.161} & -0.152 & 0.061 & \multirow[t]{10}{*}{0.414} \\
\hline \multicolumn{5}{|l|}{ Gender } & & \\
\hline Level of Education & $0.308^{*}$ & 0.001 & & $0.209 *$ & 0.008 & \\
\hline Household monthly income & 0.054 & 0.519 & & 0.014 & 0.947 & \\
\hline Duration of disease & 0.059 & 0.495 & & 0.103 & 0.261 & \\
\hline (2) Knowledge & & & & $0.205^{*}$ & 0.014 & \\
\hline Attitude & & & & 0.122 & 0.108 & \\
\hline Subjective norms & & & & 0.043 & 0.510 & \\
\hline Self-efficacy & & & & $0.306^{*}$ & 0.001 & \\
\hline Behavioral intention & & & & $0.182 *$ & 0.020 & \\
\hline
\end{tabular}

Note: *P-value is significant at the less than 0.05 . 
vigorous physical activity, whereas high education was linked with a lack of light-intensity physical activity as well as high sedentary time, especially, during weekdays. ${ }^{27}$ Furthermore, according to Sun et $\mathrm{al}^{28}$ education has a positive association with prior knowledge and health literacy. These results emphasize the need to design and implement training programs for people with low literacy levels in order to improve awareness about self-care behaviors.

A statistically significant association was found between knowledge $(P=0.014)$ and PABs. According to the findings, knowledge was the second best-reflecting factor of PABs. This finding proves that a patient with type 2 diabetes with more necessary knowledge is more likely to perform PABs. Low knowledge of health-promoting behaviors can affect the control of the disease. ${ }^{29}$ In concert with this study, Didarloo et $\mathrm{al}^{19}$ reported that knowledge was one of the strongest predictors of self-care behaviors among diabetic patients. In other studies, Corbett ${ }^{30}$ reported that knowledge was an important factor in controlling diabetes. These findings confirm the need for developing and conducting educational programs to increase people's knowledge about ways to control diabetes. Therefore, it is recommended that different programs, such as campaigns, be adopted to improve patients' knowledge about the disease.

Besides, according to the findings of the present study, self-efficacy is found to be the strongest predictor of intention to physical activity and PABs. In other words, the findings show that when an individual believes in his/her ability to perform PABs, he/she will be more interested in adopting them. Consistent with this, Didarloo et $\mathrm{al}^{19}$ reported that selfefficacy was the strongest predictor of behavioral intention and self-care behaviors among diabetic patients. ALAboudi et $\mathrm{al}^{29}$ also found that self-efficacy was a significant predictor of self-care behaviors and blood glucose control. The previous study has shown that the promotion of self-efficacy may improve health-promoting behaviors among different people. $^{31}$ Correspondingly, in another study, Lin et al ${ }^{32}$ indicated that diabetes self-efficacy might have an indirect effect on glycemic control through diabetes self-management. Considering the promotion of self-efficacy as a vital approach in planning diabetes control, educational interventions may promote PABs among diabetic patients.

As mentioned in the result section, the variables of age group and level of education had significant associations with PABs and demographic variables of the participants could reflect more than $16 \%$ of the observed variance in PABs. Yet, in the second step, ETRA constructs could predict $41.4 \%$ of the changes in the PABs, which was statistically significant $(P<0.001)$. Using ETRA among adolescents, Tavoosi et al $^{18}$ conducted a research study on drug abuse prevention behaviors; ETRA explained $28.0 \%$ of the variance of the behaviors and $36.0 \%$ of the variance of the behavioral intention. In addition, Kuochang et $\mathrm{al}^{33}$ realized that ETRA constructs could predict behavioral intention and behaviors better than the theory of reasoned action. Considering the usability of ETRA in predicting PABs in the present study, the researchers of this study may suggest that the ETRA might be a potential methodology in developing educational programs aimed at physical activity promotion among diabetic patients.

\section{Limitations}

A limitation of this study was the use of a self-reported questionnaire that could be subject to response bias. Another limitation was doing research only on type 2 diabetes patients, which may affect the generalizability of the results. Additionally, PABs were measured only over a period of 7 days, which hardly represent enduring behavior.

\section{Conclusion}

The findings of the current study showed that ETRA was a beneficial model in predicting cognitive determinants of PABs among rural type 2 diabetic patients. The PABs among rural type 2 diabetic patients in Chalderan city were low. Therefore, conducting educational intervention efforts aiming at PAB promotion is suggested. Health care providers and community health nurses in rural areas should pay much more attention to PABs among rural type 2 diabetic patients and design specific health educational programs for this population while using promising health education theories like ETRA. In order to increase motivation or intention to perform physical activity among diabetic patients, health care providers should first focus on the diabetics' self-efficacy, then intervene in subjective norms, attitudes, and other factors.

\section{Ethics approval and consent to participate}

The study protocol was reviewed and approved by the Ethics Committee of Tabriz University of Medical Sciences. Written informed consent was obtained from all participants after a full explanation of the nature, purpose, and procedures used for the study. 


\section{Acknowledgments}

There were no sources of extra-institutional commercial findings.

\section{Disclosure}

The authors report no conflicts of interest in this work.

\section{References}

1. Andrew J. Guideline and performance measures for diabetes. AJMC. 2007;13(2):41-46.

2. World Health Organization. Diabetes: Global report on diabetes; 2016. Available from: http://www.who.int/diabetes/global-report/en/. Accessed May 9, 2016.

3. Shaw JE, Sicree RA, Zimmet PZ. Global estimates of the prevalence of diabetes for 2010 and 2030. Diabetes Res Clin Pract. 2010;87 (1):4-14. doi:10.1016/j.diabres.2009.10.007

4. Didarloo AR, Shojaie Zadeh D, Eftekhar H, et al. Physical activity among women with type 2 diabetes: prediction by the extended theory of reasoned action. J Iran Inst Health Sci Res. 2012;11 (2):201-221. [Persian].

5. World Health Organization. Diabetes: key facts; 2016. Available from: http://www.who.int/mediacentre/factsheets/fs312/en/. Accessed December 4, 2016.

6. Graham JE, Stoebner-May DG, Ostir GV, et al. Health related quality of life in older Mexican Americans with diabetes: a cross-sectional study. Health Qual Life Outcomes. 2007;5(1):1. doi:10.1186/14777525-5-39

7. Adachi M, Yamaoka K, Watanabe M, et al. Effects of lifestyle education program for type 2 diabetes patients in clinics: study design of a cluster randomized trial. BMC Public Health. 2010;10(1):742. doi:10.1186/1471-2458-10-742

8. Vail-Gandolfo N. The Effects of a Motivational Program on Glycemic Control, Physical Activity and Weight Loss in Individuals with Type 2 Diabetes Mellitus. New York: Hofstra University; 2008.

9. Bassuk SS, Manson JE. Epidemiological evidence for the role of physical activity in reducing risk of type 2 diabetes and cardiovascular disease. J Appl Physiol. 2005;99(3):1193-1204. doi:10.1152/ japplphysiol.00160.2005

10. Duncan GE, Perri MG, Theriaque DW, Hutson AD, Eckel RH, Stacpoole PW. Exercise training, without weight loss, increases insulin sensitivity and postheparin plasma lipase activity in previously sedentary adults. Diabetes Care. 2003;26(3):557-562.

11. Ford ES, Herman WH. Leisure-time physical activity patterns in the US diabetic population: findings from the 1990 National Health Interview Survey - health promotion and disease prevention supplement. Diabetes Care. 1995;18(1):27-33.

12. Babazadeh T, Nadrian H, Banayejeddi M, Rezapour B. Determinants of skin cancer preventive behaviors among rural farmers in Iran: an application of protection motivation theory. J Cancer Educ. 2016;32 (3):1-9.

13. Didarloo A, Shojaeizadeh D, Ardebili HE, Niknami S, Hajizadeh E, Alizadeh M. Factors influencing physical activity behavior among iranian women with type 2 diabetes using the extended theory of reasoned action. Diabetes Metab J. 2011;35(5):513-522. doi:10.4093/dmj.2011.35.5.513

14. Michie S, Abraham C. Interventions to change health behaviours: evidence-based or evidence-inspired? Psychol Health. 2004;19 (1):29-49. doi:10.1080/0887044031000141199

15. Fishbein M. A behavioural theory approach to the relations between beliefs about an object and the attitude toward the object. Readings Attitude Theory Meas. 1967;132:389-399.
16. Ajzen I, Madden TJ. Prediction of goal-directed behavior: attitudes, intentions, and perceived behavioral control. J Exp Soc Psychol. 1986;22(5):453-474. doi:10.1016/0022-1031(86)90045-4

17. Bandura A. Self-efficacy: toward a unifying theory of behavioral change. Psychol Rev. 1977;84(2):191. doi:10.1037/0033-295X.84.2.191

18. Tavousi M, Hidarnia A, Montazeri A, Taremian F, Ghofranipour F. Modification of reasoned action theory and comparison with the original version by path analysis for substance abuse prevention among adolescents. Bimonthly J Hormozgan Univ Med Sci. 2010;14 (1):45-54.

19. Didarloo A, Shojaeizadeh D, Asl RG, Habibzadeh H, Niknami S, Pourali R. Prediction of self-management behavior among Iranian women with type 2 diabetes: application of the theory of reasoned action along with self-efficacy (etra). Iran Red Crescent Med J. 2012;14(2):86

20. Toobert DJ, Hampson SE, Glasgow RE. The summary of diabetes self-care activities measure: results from 7 studies and a revised scale. Diabetes Care. 2000;23(7):943-950.

21. Plotnikoff RC. Physical activity in the management of diabetes: population-based perspectives and strategies. Can $J$ Diabetes. 2006;30(1):52-62. doi:10.1016/S1499-2671(06)01009-4

22. Baji Z, Zamani Alavijeh F, Nouhjah S, Haghighizadeh MH. Self-care behaviors and related factors in women with type 2 diabetes. Iran $J$ Endocrinol Metab. 2015;16(6):393-402.

23. Colberg SR, Sigal RJ, Yardley JE, et al. Physical activity/exercise and diabetes: a position statement of the American Diabetes Association. Diabetes Care. 2016;39(11):2065-2079. doi:10.2337/dc16-1728

24. Gamiochipi M, Cruz M, Kumate J, Wacher NH, Group DS. Effect of an intensive metabolic control lifestyle intervention in type-2 diabetes patients. Patient Educ Couns. 2016. doi:10.1016/j.pec.2016.01.017

25. Morrato EH, Hill JO, Wyatt HR, Ghushchyan V, Sullivan PW. Physical activity in US adults with diabetes and at risk for developing diabetes, 2003. Diabetes Care. 2007;30(2):203-209. doi:10.2337/ dc06-1128

26. Hansen BH, Ommundsen Y, Holme I, Kolle E, Anderssen SA. Correlates of objectively measured physical activity in adults and older people: a cross-sectional study of population-based sample of adults and older people living in Norway. Int J Public Health. 2014;59(2):221-230. doi:10.1007/s00038-013-0472-3

27. Kantomaa MT, Tikanmäki M, Kankaanpää A, et al. Accelerometermeasured physical activity and sedentary time differ according to education level in young adults. PLoS One. 2016;11(7):e0158902. doi:10.1371/journal.pone.0158902

28. Sun X, Shi Y, Zeng Q, et al. Determinants of health literacy and health behavior regarding infectious respiratory diseases: a pathway model. BMC Public Health. 2013;13(1):1. doi:10.1186/1471-245813-261

29. ALAboudi I, Hassali MA, Shafie A, AlRubeaan K, Hassan A. Selfefficacy, self-care behaviors and glycemic control among type2 diabetic patients in Saudi Arabia. Res Social Administrative Pharm. 2014;10(5):e52. doi:10.1016/j.sapharm.2013.10.002

30. Corbett C. Research-based practice implications for patients with diabetes. Part I: diabetes knowledge. Home Healthcare Nurse. 1999;17(8):511. doi:10.1097/00004045-199908000-00011

31. Sarkar U, Fisher L, Schillinger D. Is self-efficacy associated with diabetes self-management across race/ethnicity and health literacy? Diabetes Care. 2006;29(4):823-829.

32. Lin K, Park C, Li M, et al. Effects of depression, diabetes distress, diabetes self-efficacy, and diabetes self-management on glycemic control among Chinese population with type 2 diabetes mellitus. Diabetes Res Clin Pract. 2017;131:179-186. doi:10.1016/j. diabres.2017.03.013

33. Kuo-Chang W. Predicting helmet use among adolescent motorcycle passengers-application and extension of the theory of reasoned action (Article written in chinese). J Educ Psychol. 1999;22 (1):41-60. 


\section{Publish your work in this journal}

The Journal of Multidisciplinary Healthcare is an international, peerreviewed open-access journal that aims to represent and publish research in healthcare areas delivered by practitioners of different disciplines. This includes studies and reviews conducted by multidisciplinary teams as well as research which evaluates the results or conduct of such teams or healthcare processes in general. The journal covers a very wide range of areas and welcomes submissions from practitioners at all levels, from all over the world. The manuscript management system is completely online and includes a very quick and fair peer-review system. Visit http://www.dovepress.com/testimonials. php to read real quotes from published authors. 